\title{
The Effect of Learners' Motivation on Their Reading Comprehension Skill: A Literature Review
}

\author{
*Nahid Mohseni Takaloo ${ }^{1} \&$ Mohammad Reza Ahmadi² \\ 1. English Literature Department, Payame Noor University, Tehran, Iran \\ 2. English Language Department, Shahid Beheshti University, Tehran, Iran \\ E-mail: mohseni364@yahoo.com
}

Received: March 10, 2017 Accepted: May 21, 2017 Online Published: September 20, 2017

\begin{abstract}
Motivation is one of the neglected parts of English language teaching. Teachers often forget that motivation is the basic part of learners' English language learning activities. In this sense, learners control the flow of the classroom. Without learners' motivation, there is no pulse and no life in the class. When learners learn to incorporate direct approaches to generate motivation in their learning, they will become happier and more successful learners. This paper is an attempt to investigate the impact of motivation on learners' reading comprehension. It reviews the terms motivation, different types of motivation, reading comprehension, and different models of reading comprehension. The review of the literature indicated that motivation has an influential role in learners' reading comprehension.
\end{abstract}

Keywords: motivation, types of motivation, reading comprehension, models of reading

\section{Introduction}

Motivation is an essential factor to improve reading comprehension that all of researchers and teachers admitted it. According to Dornyei (2001), the meaning of motivation is so complicated because it is composed of different models and theories. Teachers can supply an exciting and relaxed environment to increase their learners' reading comprehension. By using various genres, they are able to make a more attractive atmosphere for students. In fact the teachers are as models and motivators. They should provide a situation that students choose their materials and reading texts themselves and allocate more time to reading (Gambrell, 1996).

The aim of this study is to better guide the teachers by applying a research that correlates reading motivation with comprehension. According to previous research, there was a meaningful relationship between motivation and reading comprehension especially intrinsic motivation that could improve reading comprehension (Taboada \& Buehl, 2012).

One of the most important skills of language is reading comprehension and the students should comprehend reading passages when they are them to be successful in their academic life. Unfortunately, there is not enough attention to reading skill in Iran because students do not face with reading activities sufficiently; therefore, they are reluctant to read. Al-Jarf (2007) believed that the main cause of students' reluctance is teachers' instruction because they cannot make a challengeable reading instruction, so students face with lack of cognitive and metacognitive reading abilities. They need to comprehend reading texts well to be successful in their next employment ( $\mathrm{Ng}$, Bartlett, Chester, \& Kersland, 2013).

Reading comprehension means the perceiving of the vocabularies which are used in a written text and making a relationship between them to achieve a comprehensive understanding. Reading comprehension is a complex skill because it needs other skills such as vocabulary and decoding skills (Becker, McElvany, \& Kortenbruck, 2010).

One of the most important factors that can influence reading comprehension is motivation. In fact, the correlation between reading motivation and reading comprehension is more than reading activities and reading behavior. There were a lot of research that examined the relation between motivation and reading comprehension and it looks that there is a direct relationship between reading comprehension and reading motivation (Morgan \& Fuchs, 2007). 


\section{International Journal of Research in English Education}

Investigations emphasize on cognitive aspects such as identification of vocabulary and comprehension. The framework that all of readers use for reading comprehension is their manner to reading comprehension, so readers' manner for reading comprehension refers to their affection to reading (Alexander \& Filler, 1976). In fact, when readers have a positive manner of reading, their comprehension increases because they have more motivation to read. Other factor that is so necessary to make motivated readers is interest. Readers should have desire to reading texts (Renninger, Hidi, \& Krapp, 1992). Interest is connected to text comprehension and other essential reading results. The approach is categorized in two theoretical situations, the integrative view and achievement motivation theory. The integrative view on reading is associated with cognitive and social aspects of reading motivation (Baker, Afflerbach, \& Reinking, 1996).

Gardner and Lambert (1959) thought motivation as the knowledge to the second language acquisition society that should be emphasized more. Gardner established his Socio-Educational Model of Language Learning, which focused on Integrative Motivation. It is referred to the language learners desire to communicate with the members of society that is the most influential factor in language learning motivation. According to Dornyei (2003), there is a processoriented approach to second language motivation and the researchers should concentrate on dynamic aspects of motivation. Mori (2002) carried out a study towards reading motivation and found that integration with community plays an important role to stimulate readers to second language reading motivation. In this paper, the researchers explain motivation, review different types of motivation, elaborate reading comprehension, clarify different models of reading comprehension, and mention previous studies on the effect of motivation on reading comprehension.

\section{Motivation}

Because of the importance of students' learning and their progress in language skills, much of the time is devoted to the development of reading skill. It should be mentioned that learners try to develop their reading comprehension specially the specific group of students who don't have enough facilities and are dependent on their teachers. These students are not able to achieve good marks in reading comprehension and don't acquire it beneficially. One of the ways that can be used as a solution to motivate learners and develop their reading skill is the use of reading interference programs.

Researches indicated that cognitive and motivation variables affect students' reading comprehension (Pressley \& Harris, 2006). Previous research has advocated reading motivation in connection to students' comprehension progress because reading comprehension permits students to analyze information that they have a prior knowledge about it to increase their comprehension (Duke, Pearson, Strachan, \& Billman, 2011).

Motivation is an influence factor for achieving a special goal. Similarly, according to Ryan and Deci (2000), to be motivated means to progress or to be in motion to do something. Motivation makes acting on or within an organism to establish and manage behavior. Excitement, interest, eagerness, and looking forward to learning are the main elements of motivation. The levels and types of motivation in any individual are different from others. In other words, not only levels and amounts of motivation in individuals were different, but also their sorts of motivation could be various (Crump, 1995).

Hermosa (2002) defined reading motivation as the interest or desire to read for different purposes. She believed that positive reinforcements had beneficial impacts towards motivation in reading, so it is necessary for teachers to make integrative reading activities. According to Baker, Dreher, and Guthrie (2000), teachers and parents must supply adequate and interesting reading materials, create a sharing community of learners, make a comfortable context for learning, identify specific child's strengths and weaknesses, provide enough time to read, associate with other teachers and administrators for a general reading program, and learn the strategies for integration and effective learning.

Motivation was affected by a "combination of many factors involving trying, desire, and pleasure with the learning situation. Different types of motivation have been discussed in related literature including integrative, instrumental, intrinsic, and extrinsic motivation (Carreira, 2006).

As a result, different approaches to motivation can emphasize on cognitive behaviors (such as monitoring and strategy use), non-cognitive aspects (such as perceptions, beliefs, and attitudes), or both. For example, Gottfried (1990) defined academic motivation as "enjoyment of school learning feathered by a mastery aspect; curiosity; persistence; taskendogeny; and the learning of difficult and new tasks." 


\section{International Journal of Research in English Education}

\section{Different Types of Motivation}

Motivation is categorized into four types. They are intrinsic, extrinsic, integrative, and instrumental motivation. The following section explains motivation in more detail.

\subsection{Intrinsic Motivation}

Intrinsic motivation is the desire to do or get to something because one really wants to and takes satisfaction or see value in doing something (Usher, 2012). When a student is intrinsically motivated to read, he or she read for enjoyment, pleasure, to discover new knowledge, or for some other positive results. A student may be motivated to read for a deep interest in the content or main point of a text (object-specific), or because the text attracts the student within the story (activity-specific). Because students, who are intrinsically motivated, find pleasure in reading, they like to read more in their free time. Because of an increased amount of reading time, it is imagined that intrinsic motivation increases reading comprehension. Students would not be able to achieve complete skill in reading comprehension without intrinsic motivation (Marinak \& Gambrell, 2008).

Teachers who utilize many external factors to motivate students to read could increasingly destroy students' intrinsic motivation. Researchers contrasted intrinsic motivation with extrinsic motivation, which is motivation managed by reinforcement. Traditionally, educators considered intrinsic motivation to be more favorable and to result in better learning consequences than extrinsic motivation (Deci, Koestner, \& Ryan, 1999).

Gottfried (1990) pointed out that intrinsic motivation for reading could be defined as the enjoyment of reading activities for their own sake, which is coherent with the formulation in self-determination theory. Intrinsically motivated reading is composed of text interaction for enjoyment, to stimulate curiosity, and to gain the prizes or achieving new knowledge that may be challengeable for readers. Intrinsic motivation had been correlated to reading development based on standardized tests by several researchers for elementary school students (Baker \& Wigfield, 1999).

\subsection{Extrinsic Motivation}

Extrinsic motivation refers to the external factors that can stimulate students' desire to read. These factors involve scores, prizes, admiration, or a desire to be better than others do. Students who are extrinsically motivated naturally try to inhibit negative outcomes and only expect specific or positive outcomes. Moreover, teachers should have a positive attitude to reading comprehension to achieve the best results in reading development. This positive attitude is performed by the classroom teacher reading during personal reading, debating their enjoyment in a particular book or recommending books to students, displaying books around the classroom, or reading aloud every day. To explore students' attitudes towards reading, teachers can use many devices such as surveys, questionnaires, and classroom discussions (McGeown, Norgate, \& Warhurst, 2012).

Extrinsic motivation refers to doing something because it causes a distinguished outcome (Deci \& Ryan, 1985). According to classical literature, extrinsic motivation has typically been characterized as a pale and impoverished form of motivation that is contrasted with intrinsic motivation. In extrinsic motivation, the reader explores external merits and rewards such as to prevent the punishment of teachers or to gain appreciation from parents. In fact, extrinsic motivation is related to the goal orientation, so the students do their actions with the best way to achieve a valuable thing (Baker \& Wigfield, 1999).

\subsection{Integrative Motivation}

In integrative motivation, a person likes to be admitted by a community and has a social relationship with other people. An integrative motivation points to language learning for personal progress and cultural reinforcement that is the learner desires to learn a language to integrate successfully into the target language community. An integrative motivated learner indicates interest in learning about the culture and the people of the target language (Gardner \& Lambert, 1959).

According to Masgoret and Gardner (2003), an integrative motivated learner is the one who is motivated to learn the second language to become familiar with other language community. In parts of the world where English is acquired as a foreign language, the integrative motivation plays a slight role in the fame of English. Due to the importance of 


\section{International Journal of Research in English Education}

motivation in language learning, Sadeghi (2005) believed that teaching of English is a difficult task for both Iranian students and teachers because they lack motivation.

According to Lightbown and Spada (2000), integrative motivation refers to language learning for personal progress and cultural reinforcement. Integrative motivation occurs when the student likes to join or be a member of the certain population and the culture; moreover, the comprehensive type of motivation is the integrative motivation. Integrative motivation was more capable and well formed. Students who did not have integrative motivation, in fact, would expose with problems and difficulties to learn and get knowledge of a second language in the classroom and generally, learning the language would be more difficult for them (Cook, 2000).

\subsection{Instrumental Motivation}

According to Cook (2001), a learner with instrumental motivation learns second language to use it pragmatically such as achieving a job or gaining money. Although both integrative and instrumental motivation are essential in language learning, integrative motivation is superior to instrumental motivation for prognosticating the success of second language learning. Because students respect the target culture, they may read literature and practice language, so they are able to progress their language. Instrumental motivation is meaningful for the learner who has restricted access to L2 culture or foreign language organization, and integrative motivation is viewed more important in a formal learning environment than instrumental motivation (Oxford, 1996).

Dornyei (1996) claimed that instrumental motivation and the learners' requirement for achievement was more important than the integrative motivation. Iranian students had very high motivation and positive manners towards learning English and were more instrumentally motivated. Instrumental motivation was considered motivation as stimulating a need to learn the L2 for practical or external reasons such as achievement of goals, passing exams, financial prizes, developing a career or gaining progress. There are two main types of instrumental motivation: promotion (self-progress) and prevention (Vaezi, 2008).

\section{Reading Comprehension}

Reading comprehension is the organization of meaning of a written or spoken communication by a reciprocal, holistic exchange of ideas between the interpreters and the message in a specific communicative context. Reading comprehension is the basic decoding skill that serves the meaning of the written texts, but it is also included the prior knowledge of the reader in addition to this skill. Reading comprehension might also refer to "the ability to identify how and where to supply one's reading resources in order to increasingly achieve one's goals in a comprehension situation" (Wagner \& Sternberg, 1987). In other words, in addition to the mechanical skills of reading and the usage of the reader's prior knowledge and experience, a reader also needs to understand what is to be done with the information that is processing. If a reader "figures out all of the words and sentences, but isn't able to understand the main idea of a text," then he or she will comprehend the perfunctory meaning of the written text. This shallow comprehension happens because the reader does not have a prior knowledge about the main topic of the passage and cannot remember it to achieve a deep understanding of the written passage. If readers know that their recall of words and sentences will be examined, they devote a lot of time to comprehend the written text deeply; therefore, they are able to remember old information (Just \& Carpenter, 1987).

According to Ahmadi and Hairul (2012) and Ahmadi and Pourhossein Gilakjani (2012), reading comprehension is not an easy process because students need to be able to read the written text, decode the words, and identify the meanings of the words. Reading comprehension is one of the main significant elements in English language learning for all learners because it provides the foundation for a substantial amount of learning in education. Because reading comprehension is so logical in terms of academic success, it can be argued that motivating a student to read is essential. In order to understand the importance of what is read one must be a critical reader. Critical readers have the ability to follow the written text tactfully and can relate sentences to each other to achieve a deep understanding of it (Chapman, 1993).

Reading comprehension is an active and communicative process between the reader, the text, the reading activity, and the larger socio-cultural context for reading. An interaction occurs within the individual, including both top down and bottom up reading and cognitive strategies. A reader can comprehend and recall written text well if he or she integrates the prior knowledge with the achieved information (Zwann \& Radvansky, 1988). 


\section{International Journal of Research in English Education}

Reading comprehension relates to the academic achievement of foreign language learners and other language factors for foreign/second language learners (Grabe, 2009). Reading comprehension has stimulated many effective researches. Many studies have done on reading comprehension that indicated context and prior knowledge played a significant role in comprehending a written text. Cognitive skills, such as background knowledge and cognitive strategy use are not increasingly related to intrinsic reading motivation because readers' performance and their progress in reading comprehension are various, and intrinsic reading motivation has an influential effect on reading comprehension performance (Logan, Medford, \& Hughes, 2011b).

According to a research on second language reading, the main important factor in reading comprehension is the use of reading comprehension strategies. Prior knowledge and use of cognitive strategies has a significant attention on the items of reading comprehension teaching. Being successful in the development of reading comprehension is not an intrinsic competence, but it is attached to metacognitive strategies and reading is the most important skill of language to other skills especially where English used as a second language (Carrell, Devine \& Eskey, 1988).

\section{Different Models of Reading Comprehension}

There are three models of reading process: the bottom-up model, the top-down model, and the interactive model. These models are explained in detail respectively.

\subsection{Bottom-up Model}

According to Grabeand Stoller (2002), a bottom-up reading model is a model that focuses on a single-direction, partto-whole processing of a text. In bottom-up models, the reader is assumed to be included in a mechanical process where he or she decodes the text letter by letter, word by word, and sentence by sentence. In fact, the reader decodes the text which has been previously encoded by the writer. Decoding of the text includes noticing the details of a text for example phonemes, morphemes, words, sentences, and discourse to achieve the meaning or semantic aspect of language (Alderson, 2000).

Flesch (1955) debated that these models work on the written text hierarchically or organization of the text (coherence), and the reader's job is to process the smallest unit of language (i.e. grapho-phonic) and then coordinate the smaller units to discover and comprehend the higher linguistic units (e.g., sentence syntax).In bottom up processing, the focus is on the serious function of the lower-level recognition skills. Reading is a hierarchical process, starting from the understanding of single phonemes to words, clauses, sentences and then the whole piece of discourse. According to this processing model of reading comprehension, the reader does not miss any part of a written text and studies it consciously. Shahnazari and Dabaghi (2014) pointed out bottom up processing is data-driven and the role of the lower level recognition skills, involving orthographic, semantic, syntactic and phonological processing are very important in comprehension.

According to Iran-Nejad (1987), bottom-up is the process that is not easy to use higher-ordered reading skills such as making inferences and the reader's background knowledge plays a very restricted function in interpreting the meaning of a text. Bottom-up strategy is called local strategy or problem solving and supports strategies for readers to realize specific linguistic components. Bottom-up theory discussed that the readers make the text from the smallest units (letters to words to phrases to sentences, etc.) and the process of organizing the text from those smallest units get very automatic that readers are not conscious of the process. In bottom-up theories and models, the reading process is regarded as text-driven decoding process, so the scarce function of the reader is to reorganize meaning (McKoon \& Radcliff, 1992).

Shrum and Glisan (2000) pointed out that the text is a chain of divided words, each of them should be analyzed individually, and the reader investigates the text by focusing deeply on the combination of letters and words. Meaning is understood through synthesis of units of language and the reader processes language in a chronological order, integrates sounds or letters to form words, then combines words to form phrases, clauses, and sentences of the text; therefore, the most important skills involved are distinguishing sounds and letters, determining word order and suprasegmental structures, and translating individual words. The bottom-up model took place simultaneously with audio-lingual method of second language instruction in the 1960s and 1970s, which investigated decoding of soundsymbol relationships as an essential element of language learning. In bottom-up model, the graphemic, syntactic, 


\section{International Journal of Research in English Education}

lexical, semantic, and pragmatic codes were regarded associative with the meaning of the text, and the significance of "holding in the bottom" was focused a lot (Eskey, 1988).

\subsection{Top-down Model}

A top-down reading model is a model that emphasizes on what the reader transforms to the text to arrive at the meaning. In top-down models, it is assumed that the comprehension process is not mechanical, but actively controlled by the reader (Grabe, 2009). The processing of a text started in the mind of the reader with meaning-driven processes, or an assumption about the meaning of a text. In fact, readers determine letters and words only to justify their assumptions about the meaning of the text. In these models, the primary goal of reading is achieving meaning from the text rather than mastery of letters and words. Readers are supposed to use meaning and grammatical cues to identify strange words and are able to perceive a passage even if they do not know each word. In this perspective, the meaning of a text, which is regarded an important goal to achieve, is accessed by the reader's prior knowledge of semantic, pragmatic, syntactic and discourse elements, so he or she will be able to forecast and interpret the meaning(Alderson, 2000).

However, this opinion did not identify what mechanisms the reader applied to produce inferences or how the mental composition of comprehension worked. Hierarchically speaking, systematic synthesis of reading comprehension proposed one of the most concentrated models of reading skill called top-down or the conceptually driven processing approach. According to this model, reading was a psycholinguistic guessing game because the readers' preconceptions and background knowledge significantly influence on the lower-level processes such as orthographic and phonological processing, as well as the word recognition skill, and readers were scarcely neutral and passive receivers of the information from the text. Therefore, their background knowledge and other interpretive skills associated with the cognitive and metacognitive strategies increased lower level processing during the comprehension stage (Goodman, 1967).

This information was formed as meta-textual and conceptual representations in the learners' long-term memory. This approach emphasized on what readers added to the comprehension process. In top-down processing, readers get the information from the text, and then contrast it with their general knowledge in order to achieve meaning from the written text. According to this model, readers carry meaning to the text based on their experiential and interpretive prior knowledge. Some researchers discussed the primary assumptions of top-down processing. Studying eye movements during reading justified that even professional readers focus on most of the words printed on the text. Similarly, studies performed on readers with obvious background knowledge but lower processing skill indicated that in spite of the expectations of top-down approach, their performance was not excellent (Clarke \& Silberstein, 1977).

According to Block (1992a), in top-down models, the comprehension process is neither mechanical nor linear, but actively managed by the reader, so the major mechanisms for the processing of the text are in the mind of readers. From this perspective, readers understand letters and words only to justify their prior knowledge with reference to the meaning of the text. Finally, they can successfully decode a passage even if they do not know the meaning of the unfamiliar words within the text; moreover, top-down strategies are defined as general strategies. Global strategies are used for readers to forecast text content, organize a goal for reading, and control their reading process. Top-down strategy is characterized as a reading process, or "psycholinguistic guessing game." Readers monitor the reading text through their pre-existing schemata to perceive new words. The top-down strategy focuses on the significance of schemata that is called preconception and prior knowledge in understanding the literary work (Xia, 2011a).

Readers with share knowledge of the world can predict the meaning of the reading text, justify or reject the previous guesses, and ultimately understand the text by an inferential and constructive reading process. Top-down theory debated that readers utilize knowledge, expectations, assumptions, and questions to the text and given a basic understanding of the vocabulary, they kept on reading the text to confirm their expectations. The top-down school of reading theory argued that readers adapt the text into knowledge (cultural, syntactic, linguistic, and historical), then they turn back to check the text when new or unexpected information appear. While bottom-up models named the reading process as a decoding activity with an emphasis on the structure of the text, top-down models were reverse and noticed to the reader and his/her interests, general knowledge, and reading skills. It indicated direction to readers to understand how they should process and construct meaning from their own previously acquired knowledge (Goodman, 1968). 


\section{International Journal of Research in English Education}

\subsection{Interactive Model}

Because the information in top-down and bottom-up models do not move in one direction and the information involved in higher steps do not affect on the information in lower steps. These models can not apply for making inferences, which happened while reading. Therefore, to avoid this problem, an interactive model of reading is suggested. This model, which is an integration of both top-down and bottom up strategies, is thoroughly regarded as a comprehensive explanation of how we derive the meaning of a written text. An interactive model of reading was established which is based on this fact that meaning does not inhabit in the text alone, but is an association of the writer's text and the reader's interpretation. Thus, reading needs an interaction between the reader's mind and the writer's text. This permits the information involved in higher stages to interact with and affect the information in lower stages. In this model, the process begins the information by the eyes in the shape of visual characteristics, records in a visual information store, and exchanges to the central element of the model, the framework synthesizer at the first stage. Then different sources of information about letter forms and orthography are carried from long-term memory into short-term memory. Finally, the pattern synthesizer utilizes this information to infer the written text (Rumelhart, 1977).

According to Baddeley and Hitch (1974), the reader is included in extracting the meaning of the text and making inferences through a quick interaction between the superficial structure of the text and his own background knowledge of the topic. Since short-term memory is the place for the temporary storage and processing of information, it plays a significant role to comprehend the written text. These processes are composed of keeping the text information, activating the reader's world knowledge and remembering it from long-term memory, integrating the information received from these two sources into coordinated discourse, and finally receiving the meaning of the text. Research supported the opinion that the working memory capacity of good readers is more than the poor readers' memory. This model was a reforming pattern of previous strategies of top down and bottom up models (Cain \& Oakhill, 2006).

An interactive model moved between both bottoms-up and top-down models. It was related to the kind of text as well as on the reader's prior knowledge, language proficiency level, motivation, strategy use, and reader's attitude about reading. The word "interactive" was very well- known in the researches of reading. It was utilized for the mental processes that happened in the reader's mind, or for the interaction of elements that made the text, and it explained the different reading models. Interactive model focused on the progressive interaction between bottom-up and top-down processing in the organization of text meaning. The most common model of reading was the interactive group, that comprehension was regarded as the result of bottom-up and top-down components working in a cohesive structure to make an interaction between the reader and the text. Although interactive models confirmed the impact of textual information on the reader's mental activities, most of the researchers neglected the importance of top-down factors such as metacognition, the compensatory strategy of interest and background knowledge, and schemata. According to schemata theory, comprehension is the result of a coordination of the text and the reader's background knowledge. Specially, every input is planned against the recent schema and all aspects of that schema must be adapted with the input information (Carrell \& Eisterhold, 1988).

\section{Related Studies on the Effects of Motivation on Reading Comprehension}

Reading comprehension is one of the most essential skills that should be developed and nurtured in a child at home and in school because it is the primary factor to success in academic life. The ability to read for various goals is a prerequisite of a successful learning in schools, colleges, and universities. It is an alive and active skill in the 21st century for students or professionals. Moreover, reading is regarded as the key element of learning for academic proficiency. Therefore, being able to develop influential reading could have various impacts on learning across the curriculum, motivation to read, attitudes toward life, and performances in the work place. Reading comprehension is a complicated cognitive process. According to a theoretical perspective, reading comprehension is an interactive process of extracting meanings from a text. In fact, it is an interaction of different alternatives (reader, text, and environment) in a sociocultural context. It is composed of a set of cognitive activities such as "the comprehension of words, guessing the meaning, purposeful reaction, and integration." There are different components that influence on students' reading comprehension. Some of these are vocabulary knowledge, prior knowledge, and knowledge of grammar, metacognitive consciousness, structural knowledge, and reading strategies (Dagget \& Hasselbring, 2007). 


\section{International Journal of Research in English Education}

In addition, there are other more specific variables that can affect readers' reading performance and involve students' reading culture or motivation, the depth of integration in reading, influential teaching of comprehension techniques, high vocabulary and general knowledge, fluency, text construction or genre, opportunities for speaking and writing, and knowledge of different reading strategies. There were also three superior components in comprehension such as attention to story structure, guessing meaning, and comprehension controlling. Moreover, social and economic status in the family, coordination of a student and family, amount of reading out of school, and student's reading at school are the significant agents that influence reading progress. In addition, other factors play an effective role in academic reading comprehension such as having strong vocabulary knowledge, the knowledge of syntax, and metacognitive awareness. In addition, oral reading method positively affects students' reading performance (Trehearne \& Doctorow, 2005).

Researchers showed that the impact of technology, using Web Quests improved students' motivation and reading comprehension. Therefore, reading motivation defined as the interest or desire to read for different purposes. Positive reinforcements had beneficial impacts on reading motivation. Hence, it was necessary to design motivating and integrative reading activities for learners to increase the real love and sympathetic for reading. In addition, teachers and parents should improve students' vocabulary and guide them to supply good situations to read with adequate and attractive reading materials. Then, making a share community for the learners and a comfortable and funny context for reading, determining specific students' strengths and weaknesses, specifying ample time to read, associating with other teachers to plan a reading program, and understanding the strategies for engaging learners can motivate them for reading comprehension (Mermelstein, 2014).

According to one study that investigated the relationship between reading motivation and reading comprehension, the differences between intrinsic and extrinsic motivation were identified. That study found that intrinsic reading motivation positively affected reading ability. However, extrinsic reading motivation negatively affected reading ability. Moreover, intrinsic reading motivation increased the amount of reading comprehension than extrinsic motivation (Wigfield \& Guthrie, 1997).

It was very important to emphasize on developing intrinsic reading motivation instead of extrinsic reading motivation. Learners who read more had better reading comprehension. In fact, the amount of reading could predict reading progress. Several studies on literacy development had been implemented to figure out the development of reading comprehension of students at schools. Researchers who had spotlighted on motivation had discussed about the roles of cognitive and motivation alternatives interaction and the impact of variables on learners achievement. Moreover, recent studies focused on the developing of cognitive skills and vivacious activities to enhance learners reading motivation (Schaffner \& Ulferts, 2013).

Some of these studies had examined intrinsic motivation as a predictor of progress in several regions, such as reading, sports, and mathematics. Investigators pointed out that intrinsic motivation was a powerful predictor of elementary school students' reading comprehension, so the most important point for educators was to force readers to integrate in reading activities. As a result, making a comfortable atmosphere for the students to face with integrative activities could increase students' motivation for reading achievement (Wigfield, Eccles, Schiefele, Roeser, \& Davis Kean, 2006).

Engaged readers have the ability and knowledge about using and organizing strategies to improve their learning through reading. Using mixed method of teaching in reading classrooms, the use of strategies among students has indicated an increase in text comprehension, expanding the predictive power of this alternative on comprehension, and strong coordination with learning performance. Therefore, activating prior knowledge has a significant function in comprehension of classical printed texts (Pressley, 2000).

In the Pakistani context, different studies had been conducted on learning motivation. Research with school-age L1 readers indicated that intrinsic and extrinsic motivations effectively were related to reading progress, strategy use, and text comprehension. However, intrinsic motivation could display more effective role in reading achievement and better text comprehension, although there were other factors that could be influential such as students' ethnic backgrounds and learners age (Unrau \& Schlackman, 2006).

Connections between motivation and actual reading behaviors had been examined in several L2 researches. For example, positive correlations between intrinsic motivation and reading amount were achieved with EFL students in 


\section{International Journal of Research in English Education}

Japan, Sri Lanka, and Turkey. Extrinsic motivation also positively correlated with reading amount, but generally to a lower average. With fifth-grade bilingual students in Hong Kong, students' L2 reading comprehension was forecasted only by an extrinsically orientation (i.e., Instrumentalism); moreover, there weren't any significant correlations between motivation and text comprehension with EFL students in Japan (Dhanapala, 2006).

According to one study that investigated the relationship between motivation and reading comprehension, the findings indicated that there was a significant correlation between intrinsic motivation and learners reading development. In fact motivated learners had more eagerness for reading texts. There was little research that studied the connection between motivation and reading comprehension (Jafari \& Shokrpour, 2012).

\section{Conclusion}

According to the review of the literature of this research, it can be stated that motivation is one of the most essential factors that has a direct impact on the development of reading comprehension, but the teachers need to know that the students are motivated differently. They should make the classroom as an enjoyable space to motivate them and increase their confidence, spontaneity, autonomy, and self- stimulation. Teachers need to pay attention to students' interests and their requirements. Students are very much interested in any reading material that is with humor, fun, enjoyment, and pleasure. This means that they prefer reading for entertainment purposes. This implies that teachers need to integrate fun in reading instruction. Motivation is an essential factor to develop English reading comprehension. Teachers should provide appropriate environment to increase students' motivation in reading comprehension. They can use various genres; permit the students to choose the materials that are yielded based on their needs and interests. In fact, teachers are the real models and motivators in arousing students' motivation. They should specify much time to reading. Based on the literature review of this study, it can be concluded that the schools, universities, and all of the educational institutions should specifically focus their students' attention on the important role of motivation in reading comprehension in their instructional courses.

\section{References}

Ahmadi, M. R., \& Hairul, N. I. (2012). Reciprocal teaching as an important factor of improving reading comprehension. Journal of Studies in Education, 2(4), 153-173. doi: https://doi.org/10.5296/jse.v2i4.2584

Ahmadi, M. R., \& Pourhossein Gilakjani, A. (2012). Reciprocal teaching strategies and their impacts on English reading comprehension. Theory and Practice in language Studies, 2(10), 2053-2060. doi:10.4304/tpls.2.10.2053-2060.

Alderson, J. C. (2000). Assessing reading. Reading in a foreign language. Cambridge: Cambridge University Press. https://doi.org/10.1017/CBO9780511732935

Alexander, J. E., \& Filler, R. C. (1976). Attitudes and reading. International Reading Association, Newark, DE.

Al-Jarf, R. (2007). Developing reading and literacy in Saudi Arabia. Retrieved from ksu.edu.sa/jspui/handle/123456789/7709.

Baddeley, A. D., \& Hitch, G. (1974). Recent advances in learning and motivation. In G.A. Bower (Ed.), The psychology of learning and motivation: Volume 8. Advances in research and theory (pp. 47-89). New York: Academic Press.

Baker, L., Afflerbach, P., \& Reinking, D. (1996). Developing engaged readers in school and home communities: An overview. In L. Baker, P. Afflerbach, \& D. Reinking (Eds.), Developing engaged readers in school and home communities (pp. xiii-xxvii). Mahwah, NJ: Erlbaum.

Becker, M., McElvany, N., \& Kortenbruck, M. (2010). Intrinsic and extrinsic reading motivation as predictors of reading literacy: A longitudinal study. Journal of Educational Psychology, 102(4), 773-785. doi: 10.1037/a0020084.

Baker, L., Dreher, M. J., \& Guthrie, J. T. (2000). Engaging young readers: promoting achievement and motivation. New York: Guilford Press. 


\section{International Journal of Research in English Education}

Baker, L., \& Wigfield, A. (1999). Dimensions of children's motivation for reading and their relations to reading activity and reading achievement. Reading Research Quarterly, 34(4), 452-477. doi: 10.1598/RRQ.34.4.4.

Block, E. L. (1992a). See how they read: Comprehension monitoring of L1 and L2 readers. TESOL Quarterly, 26(2), 319-343. doi: 10.2307/3587008.

Cain, K., \& Oakhill, J. (2006). Assessment matters: Issues in the measurement of reading comprehension. British Journal of Educational Psychology, 76(4), 697-708. doi: 10.1348/000709905x69807.

Carreira, J. M. (2006). Relationships between motivation for learning English and foreign language anxiety: A pilot $\begin{array}{lllll}\text { study. HALT Hokkaido } & \text { Journal, } & 10, & 16-28 .\end{array}$ https://jalthokkaido.net/pluginfile.php/51/course/section/41/Matsuzaki.pdf

Carrell, P., \& Eisterhold, J. (1988). Schema theory and ESL writing. In P. Carrell, J. Devine, \& D. Eskey (Eds.), Interactive Approaches to Second Language Reading. Cambridge, UK: Cambridge UP. pp. 73-92.

Chapman, A. (1993). Making sense: Teaching critical reading across the curriculum. College Board, New York, NY.

Clarke, M., \& Silberstein, S. (1977). Toward a realization of psycholinguistics principals for the ESL class. New York: Methuen.

Cook, V. (2000). Linguistics and second language acquisition. Beijing: Foreign Language Teaching and Research Press and Macmillan Publishers Ltd.

Cook, V. (2001). Second language learning and language teaching (3rd ed). Oxford University Press.

Crump, C. A. (1995). Motivating students: A teacher's challenge. Sooner Communication Conference, Norman, Oklahoma.

Dagget, W., \& Hasselbring, T. (2007). What we know about adolescent reading. International Center for Leadership in Education. Retrieved from http://www.leadered.com/pdf/what_we_know_about_adolesent_reading_2014. Pdf.

Deci, E. L., Koestner, R., \& Ryan, R. M. (1999). A meta-analytic review of experiments examining the effects of extrinsic rewards on intrinsic motivation. Psychological Bulletin, 125(6), 627-668.

Deci, E. L., \& Ryan, R. M. (1985). Intrinsic motivation and self-determination in human behavior. New York: Plenum.

Dhanapala, K. V. (2006). Intrinsic motivation, extrinsic motivation and L2 reading comprehension of university learners in Japan and Sri Lanka. Proceedings of the JACET Summer Seminar, Japan, 6, 39-43.

Dornyei, Z. (1996). Moving language learning motivation to a longer platform for theory and practice. In R. Oxford, (Ed.), Language Learning Motivation: The New Century (pp. 71-80).

Dornyei, Z. (2001). Teaching and researching motivation. Harlow. England: Longman.

Dornyei, Z. (2003). Attitudes, orientations, and motivations in language learning: Advances in theory, research, and applications. Language Learning, 53(1), 3-32. doi: 10.1111/1467-9922.53222.

Duke, N. K., Pearson, P. D., Strachan, S. L., \& Billman, A. K. (2011). Essential elements of fostering and teaching reading comprehension. In B. Samuels, S. J., \& Arstrup, A. E. (Eds.), What Research Has to Say About Reading Instruction? ${ }^{\text {th }}$ Edition, pp. 51-93.

Eskey, D. E. (1988). Holding in the bottom: An interactive approach to the language problems of second language readers. In P. Carrell, J. Devine, \& D. Eskey (Eds.), Interactive Approaches to Second Language Reading. Cambridge, UK: Cambridge UP. pp. 93-100.

Flesch, R. (1955). Why Johnny can't read? New York: Harper and Row.

Gambrell, L. B. (1996). Creating classroom cultures that foster reading motivation. The Reading Teacher, 50(1), 1425. http://www.jstor.org/stable/20201703.

Gardner, R. C., \& Lambert, W. E. (1959). Motivational variables in second-language acquisition. Canadian Journal of Psychology, 13(4), 266-272. http://dx.doi.org/10.1037/h0083787. 


\section{International Journal of Research in English Education}

Goodman, K. (1967). Reading: A psycholinguistic guessing game. Journal of the Reading Specialist, 6(4), 126-135. http://dx.doi.org/10.1080/19388076709556976.

Goodman, K. S. (1968). The psychological nature of the reading process. Detroit: Wayne State UP.

Gottfried, A. E. (1990). Academic intrinsic motivation in young elementary school children. Journal of Educational Psychology, 82(3), 525-538. http://dx.doi.org/10.1037/0022-0663.82.3.525.

Grabe, W. (2009). Reading in a second language; Moving from theory to practice. New York: Cambridge University Press.

Grabe, W., \& Stoller, F. L. (2002). Teaching and researching reading. Harlow: Pearson Education Ltd.

Hermosa, N. (2002). The psychology of reading. Quezon City: University of the Philippines Open University.

Iran- Nejad, A. (1987). The schema: A long-term memory structure or a transient structural phenomenon. In R. J. Tierney, P. L. Andres, \& J. N. Mitchell (Eds.), Understanding readers' understanding: Theory and practice, 109-127. NJ: Lawrence Erlbaum.

Jafari, S. M., \& Shokrpour, N. (2012). EAP students' reading motivation of English academic expository texts: A mixed methods design. International Journal of Linguistics, 4(4), 372-392. doi: 10.5296/ij1.v4i4.2459.

Just, M. A., \& Carpenter, P. A. (1987). The psychology of reading and language comprehension. Boston, MA: Allyn \& Bacon.

Lightbown, P. M., \& Spada. N. (2000). Factors affecting second language learning. In Candlin, C. N. \& Mercer, N. (Eds.), English language teaching in its social context. London: Routledge.

Logan, S., Medford, E., \& Hughes, N. (2011). The importance of intrinsic motivation for high and low ability readers' reading comprehension performance. Learning and Individual Differences, 21(1), 124-128. doi: 10.1016/j.lindif.2010.09.011.

Marinak, B. A., \& Gambrell, L. B. (2008). Intrinsic motivation and rewards: What sustains young children's engagement with text? Literacy Research and Instruction, 47(1), 9-26. doi: 10.1080/19388070701749546.

Masgoret, A., \& Gardner, R. C. (2003). Attitudes, motivation, and second language learning: A meta-analysis of studies conducted by Gardner and associates. Language Learning, 53(1), 123-164.

McGeown, S. P., Norgate, R., \& Warhurst, A. (2012). Exploring intrinsic and extrinsic reading motivation among very good and very poor readers. Educational Research, 54(3), 309-322. doi:10.1080/00131881.2012.710089.

McKoon, G., \& Radcliff, R. (1992). Interference during reading. Psychological Review, 99(3), 440-460.

Mermelstein, A. D. (2014). Improving EFL learners' reading levels through extensive reading. The Reading Matrix, $14(2), 227-242$.

Morgan, P. L., \& Fuchs, D. (2007). Is there a bidirectional relationship between children's reading skills and reading motivation? Exceptional Children, 73(2), 165-183. doi: 10.1177/001440290707300203.

Mori, S. (2002). Redefining motivation to read in a foreign language. Reading in a Foreign Language, 14(2), 95-106. https://eric.ed.gov/?id=EJ661197

Ng, C. H. C., Bartlett, B., Chester, I., \& Kersland, S. (2013). Improving reading performance for economically disadvantaged students: combining strategy instruction and motivational support. Reading Psychology, 34(3), 257-300. http://dx.doi.org/10.1080/02702711.2011.632071.

Oxford, R. (1996). Language learning motivation: expanding the theoretical framework. Modern Language Journal, 78(1), 12-28. doi: 10.2307/329249

Pressley, M. (2000). What should comprehension instruction be the instruction of? In M. L. Kamil, P. B. Mosenthal, P. D. Pearson \& R. Barr (Eds.), Handbook of Reading Research, (3), pp. 545-561. Mahwah, NJ: Erlbaum.

Pressley, M., \& Harris, K. R. (2006). Cognitive strategies instruction: From basic research to classroom instruction. In P. A. Alexander \& P. H. Winne (Eds.), Handbook of Educational Psychology, 2nd ed., pp. $265-286$. Mahwah, NJ: Erlbaum. 


\section{International Journal of Research in English Education}

Renninger, K. A., Hidi, S., \& Krapp, A. (1992). The role of interest in learning and development. Hillsdale, NJ: Erlbaum.

Rumelhart, D. E. (1977). Toward an interactive model of reading. In S. Dornic (ed.), Attention and Performance IV. New York, NY: Academic Press.

Ryan, R. M., \& Deci, E. L. (2000). Self-determination theory and the facilitation of intrinsic motivation, social development, and well-being. American Psychologist, 55, 68-78. http://dx.doi.org/10.1037/0003066X.55.1.68

Sadeghi, F. (2005). Effects of attitude and motivation on the use of language learning strategies by Iranian EFL university students. Journal of Social Sciences and Humanities of Shiraz University, 23(1), 71-80. www.sid.ir/en/VEWSSID/J_pdf/103120064607.pdf

Schaffner, E., \& Ulferts, H. (2013). Reading amount as a mediator of the effects of intrinsic and extrinsic reading motivation on reading comprehension. Reading Research Quarterly, 48(4), 369-385. doi: 10.1002/rrq.52.

Shahnazari, M. T., \& Dabaghi, A. (2014). A critical overview of models of reading comprehension with a focus on cognitive aspects. Iranian Journal of Research in English Language Teaching, 1(3), 7-19. http://journals.khuisf.ac.ir/relp/article-1-76-en.html.

Shrum, J. L., \& Glisan, E. W. (2000). Teacher's handbook. Boston: Heinle \& Heinle.

Taboada, A., \& Buehl, M. M. (2012). Teachers' conceptions of reading comprehension and motivation to read. Teachers and Teaching: Theory and Practice, 18(1), 101- 122. doi:10.1080/13540602.2011.622559.

Trehearne, M. P., \& Doctorow, R. (2005). Reading comprehension: strategies that work. Comprehensive Literacy Resource: Grade 3-6 (Chapter 2). Retrieved from https://www.hand2mind.com/pdf/miriam/ch2_clr3_6.pdf.

Unrau, N., \& Schlackman, J. (2006). Motivation and its relationship with reading achievement in an urban middle school. Journal of Educational Research, 100(2), 81-101. http://dx.doi.org/10.3200/JOER.100.2.81-101

Usher, A. (2012). What is motivation and why does it matter? Washington, D.C.: Center on Education Policy.

Vaezi, Z. (2008). Language learning motivation among Iranian undergraduate students. World Applied Sciences Journal, 5(1), 54-61.https://pdfs.semanticscholar.org/eb9e/12ef5e6e82f851db76c29ad0e6e46563666a.pdf

Wagner, R. K., \& Sternberg, R. J. (1987). Executive control in reading comprehension. In B. K. Britton \& S. M. Glyn (Eds.), Executive Control Processes in Reading, pp. 1-21. Hillsdale, NJ: Erlbaum.

Wigfield, A., \& Guthrie, J. T. (1997). Relations of children's motivation for reading to the amount and breadth or their reading. Journal of Educational Psychology, 89, 420-432. http://dx.doi.org/10.1037/0022-0663.89.3.420. https://eric.ed.gov/?id=EJ553137

Wigfield, A., Eccles, J. S., Schiefele, U., Roeser, R. W., \& Davis Kean, P. (2006). Development of achievement motivation. In W. Damon \& R. M. Lerner (Eds.), Handbook of Child Psychology (6th Ed), (3), pp. 933-1002. New Jersey: Wiley Online Library. http://dx.doi.org/10.1002/9780470147658.chpsy0315.

Xia, Y. (2011a). Efficient reading in standardized tests for EFL learners: A case study of reading strategies used by Chinese English major students in TEM-4. Doctoral dissertation, Kristianstad University.

Zwann, R. A., \& Radvansky, G. A. (1988). Situation models in language and reading comprehension. Psychological Bulletin, 123(2), 162-185. 